\title{
Lip and Oral Cavity Cancer by AJCC v6 and v7 Stage
}

National Cancer Institute

\section{Source}

National Cancer Institute. Lip and Oral Cavity Cancer by A/CC v6 and v7 Stage. NCI

Thesaurus. Code C132736.

A term that refers to the staging of lip and oral cavity carcinoma according to the American Joint Committee on Cancer, 6th and 7th editions. 